\title{
Template Transfer Nanoimprint for Uniform Nanopores and Nanopoles
}

\author{
Jianjun Li, ${ }^{1}$ Weiwei Zhang, ${ }^{1}$ Yujun Song, ${ }^{1,2}$ Weiting Yin, ${ }^{2}$ and Tao Zhang ${ }^{2}$ \\ ${ }^{1}$ Center for Modern Physics Technology, Engineering Center for Weak Magnetic Detection Beijing, Department of Physics, \\ School of Mathematics and Physics, University of Science and Technology Beijing, Beijing 100083, China \\ ${ }^{2}$ School of Materials Science and Engineering, Beihang University, Beijing 100191, China
}

Correspondence should be addressed to Yujun Song; songyj@ustb.edu.cn

Received 11 November 2015; Revised 29 December 2015; Accepted 30 December 2015

Academic Editor: Mahaveer Kurkuri

Copyright (C) 2016 Jianjun Li et al. This is an open access article distributed under the Creative Commons Attribution License, which permits unrestricted use, distribution, and reproduction in any medium, provided the original work is properly cited.

\begin{abstract}
A new methodology is developed for the fabrication of nanostructures on substrate based on anodized $\mathrm{Al}_{2} \mathrm{O}_{3}$ ( $\mathrm{AAO}$ ) porous template transfer process. It includes (1) forming amorphous alloy, negative UV-resist resin (i.e., SU-8), or PMMA (polymethylmethacrylate) plate nanorod arrays by hot-press molding amorphous alloy, negative UV-resist resin (i.e., SU-8), or PMMA plate into the anodized $\mathrm{Al}_{2} \mathrm{O}_{3}$ porous substrates; (2) removing AAO templates by chemical etching process after suitable posttreatment (annealing and/or irradiation) to improve the mechanical strength of the nanorod arrays; (3) reforming nanopore films by hot-embossing the nanorod arrays into a thin layer of polymer film on substrates (e.g., silica); (4) cleaning the bottom residues in pores of the films by oxygen plasmon. The results indicate that the diameters of amorphous alloy (or negative UVresist resin or PMMA) nanorod arrays can be ranged from $32 \mathrm{~nm}$ to $200 \mathrm{~nm}$. The diameters of the imprinted ILR-1050 photoresist nanopores are about $94.5 \pm 12.2 \mathrm{~nm}$ and the diameters of the imprinted or SU-8 resin on glass slides nanopores are about $207 \pm$ $26.4 \mathrm{~nm}$, which inherit the diameters of AAO templates. This methodology provides a general method to fabricate nanorods arrays and/or thin nanopore films by template transfer nanoimprint process.
\end{abstract}

\section{Introduction}

Nanostructural materials with defined size (from $1 \mathrm{~nm}$ to $1000 \mathrm{~nm}$ ), shapes (e.g., triangle, square, or pores), and structures (e.g., monolayer, multilayers, and hierarchical arrays) have shown unique properties for advanced applications [14]. For instance, the ordered Ag nanopole arrays on Si wafer preserve surface-enhanced Raman scattering, which can be used for ultrasensitive bio/chemical sensing [5]. The surfaceconfined Ag NPs (nanoparticles) show distinct blue shift in the UV-Vis absorption [2]. Periodic nanoporous films constructed by multilayered $\mathrm{Ag} / \mathrm{CoFeB} / \mathrm{Ag}$ structures have enhanced magnetooptical effects [6]. Controlled fabrication of nanostructural materials at large scale is the base for their applications. For this goal, lots of methods have been developed, such as nanoimprint, template fabrication, lithography using electron beam, ion beam, X-ray beam, and laser beam. Among them, nanoimprint is powerful due to its large-scale ability at low cost.
The success of nanoimprint critically depends on the fabrication of robust and durable master molds and/or the development of economical fabrication technologies for these molds or direct imprinting [7-11]. Even though the conventional fabrication methods including electron, ion, X-ray, laser-beam or optical lithography can be used to fabricate the master molds besides directly conducting nanoimprint for some desired nanostructures, they are limited by either their feature sizes or patterned area scales [12-16]. Most of the current polymer master molds are not so strong and durable for increased repeating times and crystalline metal master molds are limited by their grain sizes $[17,18]$. Silicon or quartz based molds can retain their high strength over a wide temperature range and can be lithographically patterned. However, they are brittle and have limited longevity [7]. Recently, templateassisted lithography has been further developed for largescale fabrication of defined nanostructures at low cost. Particularly, anodized porous alumina makes it possible to prepare porous master molds with areas as large as $28 \times 45 \mathrm{~cm}^{2}$ 


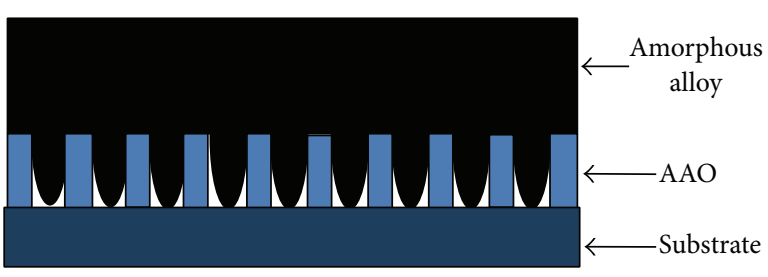

(a)

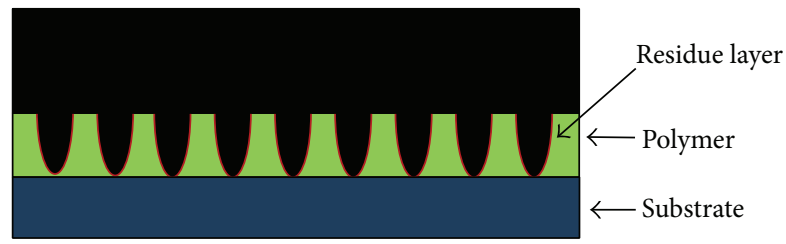

(c)

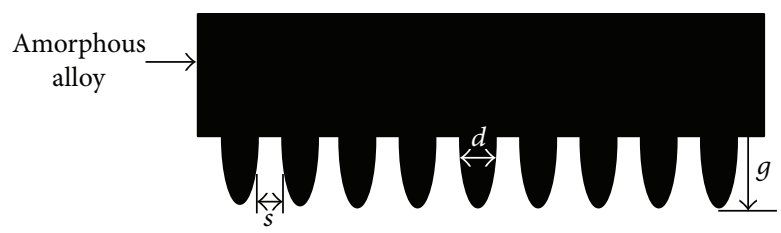

(b)

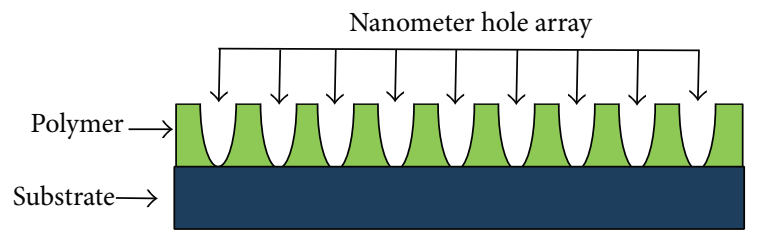

(d)

FIGURE 1: Scheme of the template transfer imprinting process for the preparation of nanopore structures. Forming amorphous alloy (or PMMA) nanorod arrays by hot-press molding amorphous alloy (or PMMA) into AAO porous substrates (a); removing AAO templates by chemical etching process (b); reforming nanopore films by hot-embossing the nanorod arrays into polymer film on substrates (c); cleaning the bottom residues in pores of the films by oxygen plasmon (d).

and feature sizes as small as $13 \mathrm{~nm}$ (products brochure of Synkera Technologies Inc.). However, most of the templates are disposable and the nanoimprint process in which we use the master molds made of traditional materials does not improve replicability, which significantly affect the stability and reliability of the final products.

It is well-known that amorphous metals and thermalsetting polymers are intrinsically free from grain size limitations and they are robust enough [8, 19-23]. Furthermore, amorphous metals present superior mechanical properties and some thermal-plastic polymers can become thermalsetting by posttreatment at high temperature and/or irradiation (i.e., UV photoresist) after they form the desired patterns $[1-4,8]$. In this paper, a new method termed as template transfer nanoimprint is developed for the fabrication of nanostructures on substrate based on AAO template transfer process in which a kind of amorphous metal alloy (i.e., Ptbased amorphous alloy) or a kind of robust epoxy resin photoresist (i.e., SU-8) is used.

\section{Experiment}

2.1. Chemicals and Materials. Double-side anodized $\mathrm{Al}_{2} \mathrm{O}_{3}$ (AAO) porous templates with pore sizes of $35 \mathrm{~nm}, 90 \mathrm{~nm}$, and $200 \mathrm{~nm}$ were purchased from Synkera Technologies. Photoresist SU-8-2050 was purchased from MicroChem Inc. Platinum, copper, and nickel bulk with purity of $99.99 \%$ were purchased from Zhongnuo Advanced Material Company. Red phosphorus (99.99\%) and 1,1,1,3,3,3-hexamethyldisilazane (HMDS) were purchased from Alfa Aesa. PMMA (polymethylmethacrylate) is purchased from Alibaba. Positive photoresist ILR-1050 was purchased from Research Semiconductor Company.

2.2. Preparation of Pt-Based Bulk Amorphous Alloy. The Ptbased amorphous plates $(\varnothing 4 \mathrm{~mm} \times 1 \mathrm{~mm})$ were prepared by cutting the Pt-based amorphous rods that were prepared by a rapid solidification process after pressing the molten alloy into a copper mold of diameter of $4 \mathrm{~mm}$. An ingot with composition of $\mathrm{Pt}_{57.5} \mathrm{Cu}_{14.7} \mathrm{Ni}_{5.3} \mathrm{P}_{22.5}$ (atom\%) [23-25] was prepared, using a high-frequency induction melting (HFIM) process (NEW-ADR-05) in which bulk platinum, copper, nickel, and red phosphorus were melted together to produce an alloy. To ensure chemical and structural homogeneity and purification, the ingot was remelted $3 \sim 5$ times with $\mathrm{B}_{2} \mathrm{O}_{3}$ under Ar atmosphere in an arc melting furnace. Then, the ingot was remelted again and Pt amorphous rods with a diameter of $4 \mathrm{~mm}$ were prepared by copper mold casting process. These rods were cut into $1 \mathrm{~mm}$ thick pieces, which will be polished and cleaned in acetone, ethanol, and deionized water for further use.

2.3. Template Transfer Process for the Fabrication of Nanopore Structures. Figure 1 gives the scheme of the template transfer imprint process for the preparation of nanopore arrays using amorphous alloy as constructing materials. The AAO templates are firstly cleaned before using as follows: immersing in acetone for $15 \mathrm{mins}$ and then in ethanol at $70^{\circ} \mathrm{C}$ for $15 \mathrm{mins}$, and then washing in deionized water, drying by $\mathrm{N}_{2}$ flow, and then placing in an oven at $80^{\circ} \mathrm{C}$ for 10 mins. Then, the Ptbased amorphous plate $(\varnothing 4 \mathrm{~mm} \times 1 \mathrm{~mm})$ is pressed into the cleaned AAO template at the temperature higher than its $T_{g}$ (glass transition temperature) but lower than its $T_{x}$ (the initial crystallization temperature) under a certain pressure that can overcome the capillary forces (a). And then the AAO template and the amorphous plate are immersed in $35 \% \mathrm{KOH}$ etching solution at $80^{\circ} \mathrm{C}$ for 30 mins to remove the AAO template, leading to the formation of nanorod arrays with desired diameter and interrod spacing (b). After that, the formed nanorod arrays can be used as master mold to form nanopore arrays again by hot embossing into a layer of polymer (e.g., positive photoresist ILR-1050 or SU-8) on substrates (c). 


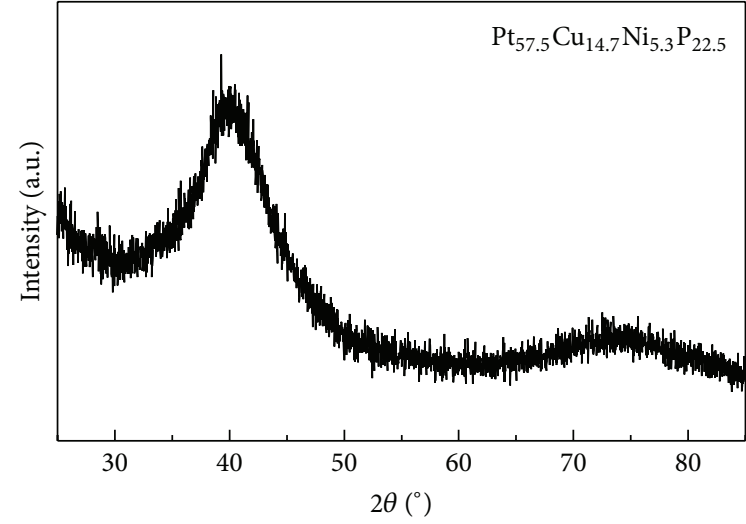

(a)

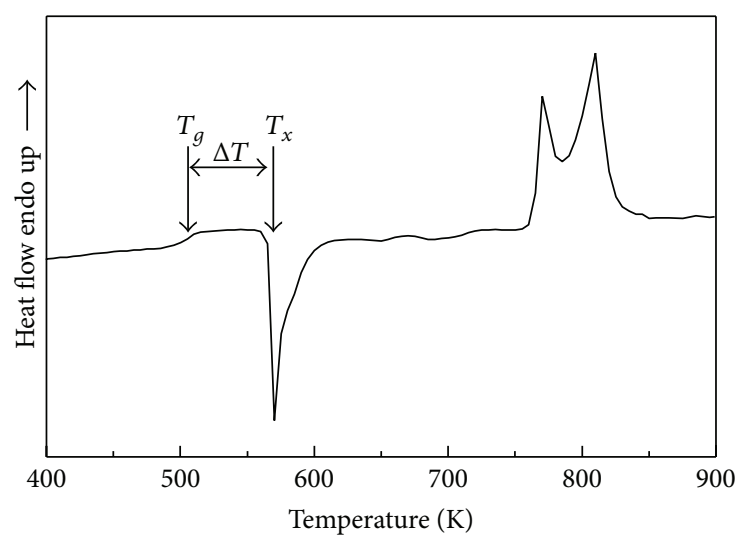

(b)

FIgURE 2: XRD pattern for the $\mathrm{Pt}_{57.5} \mathrm{Cu}_{14.7} \mathrm{Ni}_{5.3} \mathrm{P}_{22.5}$ amorphous alloy (a); DSC curves for the $\mathrm{Pt}_{57.5} \mathrm{Cu}_{14.7} \mathrm{Ni}_{5.3} \mathrm{P}_{22.5}$ bulk metallic glasses (b).

Finally, the bottom residues in nanopores after the master mold is released can be removed by oxygen plasma to obtain bottom clean nanopore arrays for further application (d). The Pt-based amorphous plate can be replaced by SU- 8 based or PMMA based plate to fabricate nanorod arrays, which can also be used to prepare the nanopore structures.

\section{Results and Discussion}

In order to make sure the Pt-based alloy be in amorphous phase, X-ray diffraction (XRD) of the Pt-based alloy rods was performed. As shown in Figure 2(a), two broadly diffused peaks at $41.0^{\circ}$ and $74.8^{\circ}$ appear in the XRD pattern, indicating that amorphous $\mathrm{Pt}_{57.5} \mathrm{Cu}_{14.7} \mathrm{Ni}_{5.3} \mathrm{P}_{22.5}$ alloy rods are prepared [23-25]. In order to find the suitable temperature range for the hot press process, the differential scanning calorimetry (DSC) is conducted. As shown in Figure 2(b), there is a typical glass transition at $502 \mathrm{~K}\left(T_{g}\right)$ and the initial crystallization appears at $570 \mathrm{~K}\left(T_{x}\right)$ for the amorphous $\mathrm{Pt}_{57.5} \mathrm{Cu}_{14.7} \mathrm{Ni}_{5.3} \mathrm{P}_{22.5}$ alloy. Thus, the super cooled liquid region is about $68 \mathrm{~K}$, which provides us with a wide enough temperature range to do the hot press.

In the template transfer process, the cleaned AAO template covered with Pt-based amorphous alloy plate is preheated at the temperature between $T_{g}$ and $T_{x}$ (i.e., $533 \mathrm{~K}$ ). Then, pressure $(80 \sim 130 \mathrm{MPa})$ is applied on the amorphous alloy plate and maintained about 60 seconds. And then the sample is removed from the oven and quenched in cold water. If the aspect ratio (length to diameter ratio: $L / d$ ) of the nanorods is low $(<7)$, the amorphous alloy plate can be easily separated from the AAO template due to their different thermal coefficients (usually, Pt-based amorphous alloy is smaller than AAO). For high aspect ratio, the AAO template can be dissolved into hot concentrated $\mathrm{KOH}$ solution $\left(80^{\circ} \mathrm{C}\right.$, $35 \mathrm{wt} \%)$. It is found that the applied pressure is increased as the diameter of AAO template decreases. For example, the applied pressure is about $80 \mathrm{MPa}$ for AAO templates with diameter of $200 \mathrm{~nm}$ and the pressure has to be increased up to $130 \mathrm{MPa}$ for AAO templates with diameter of $35 \mathrm{~nm}$.
Figure 3 gives the SEM images of the formed Ptbased amorphous alloy nanorod arrays transferred from AAO templates of different diameters. The nanorod arrays almost inherit the size and size distribution features of the nanopores. The diameter of nanorod arrays is about $199.8 \pm$ $25.8 \mathrm{~nm}$ if AAO templates with diameter of $202.4 \pm 27.8 \mathrm{~nm}$ are used (Figure 3(a)). The diameter of the nanorods is $87.8 \pm$ $6.7 \mathrm{~nm}$ if AAO templates with diameter of $88.6 \pm 6.8 \mathrm{~nm}$ are used (Figure 3(c)). The diameter of nanorod arrays is about $32.0 \pm 2.3 \mathrm{~nm}$ if AAO templates with diameter of $34.8 \pm$ $2.4 \mathrm{~nm}$ are used (Figure 3(e)). As observed from the angletilt image of some nanorod arrays (Figure 3(b) and inset of Figure $3(\mathrm{~d}))$, the aspect ratio can reach about 5-6, indicating that the $\mathrm{Pt}_{57.5} \mathrm{Cu}_{14.7} \mathrm{Ni}_{5.3} \mathrm{P}_{22.5}$ amorphous alloy has good super-plastic forming ability in its cooled liquid region, which endows it excellent filling ability even in very small pores.

We also try to obtain thermosetting polymer nanorod arrays using AAO template transfer process in which a kind of UV curing epoxy resin (i.e., SU-8) or PMMA plates is used as constructing materials $[26,27]$. If using PMMA plates as construction materials, the similar process as using Pt-based amorphous alloys can be performed for the PMMA nanorod arrays, only by adjusting the imprinting temperature to $160^{\circ} \mathrm{C}$ and the imprinting pressure at about $25 \mathrm{MPa}$. If using liquid SU-8 resin, the process is followed below. The liquid SU-8 resin of $0.5 \sim 1 \mathrm{~mm}$ thick is spin-coated on the glass substrate and dried by heating at $90^{\circ} \mathrm{C}$ for 35 mins, respectively. Then the $\mathrm{SU}-8$ resin is placed on the AAO template and pressure gradually up to $1.5 \mathrm{MPa}$ is applied on the substrate and is maintained for 5 mins. After that, the sample is exposed under UV-light for 10 mins and thermal-cured at $90^{\circ} \mathrm{C}$ for 35 mins to complete cross-linking. Finally, the AAO template is removed by dissolving into $35 \mathrm{wt} \% \mathrm{KOH}$ solution or peeled mechanically to obtain nanorod arrays made of highly crosslinked SU-8 resin. Figures 4(a) and 4(b) give the SEM images of nanorod arrays made of SU8 resin transferred from AAO template pore diameter of $82.4 \pm 3.4 \mathrm{~nm}$. The diameter of these nanorods is about $82.1 \pm 3.2 \mathrm{~nm}$, almost the same as that of the AAO template. Figures 4(c) and 4(d) give the SEM 


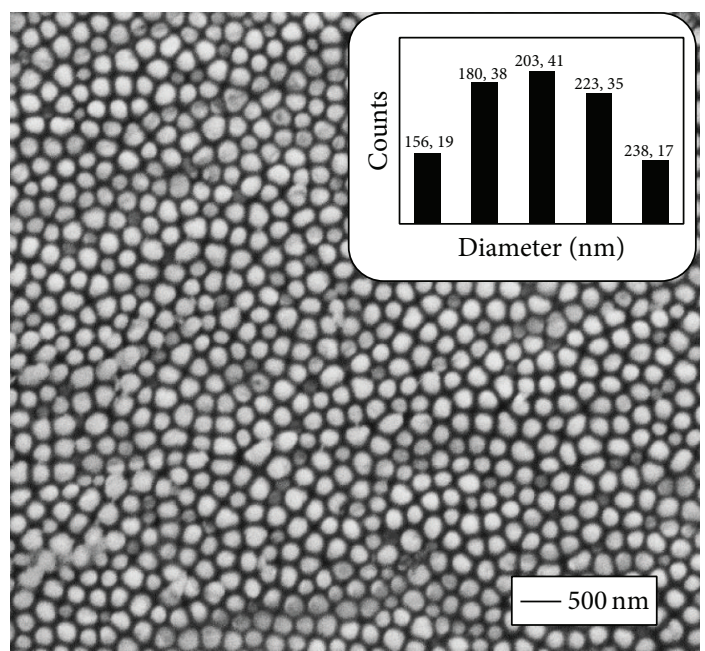

(a)

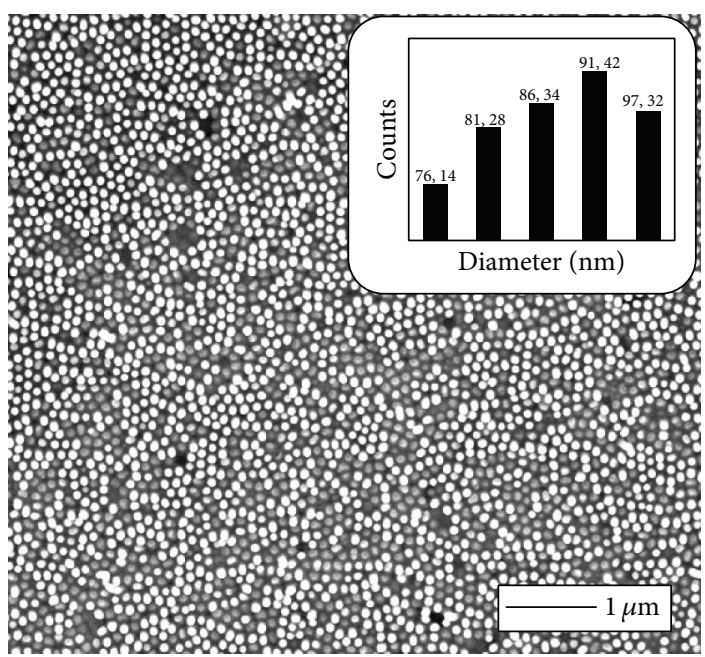

(c)

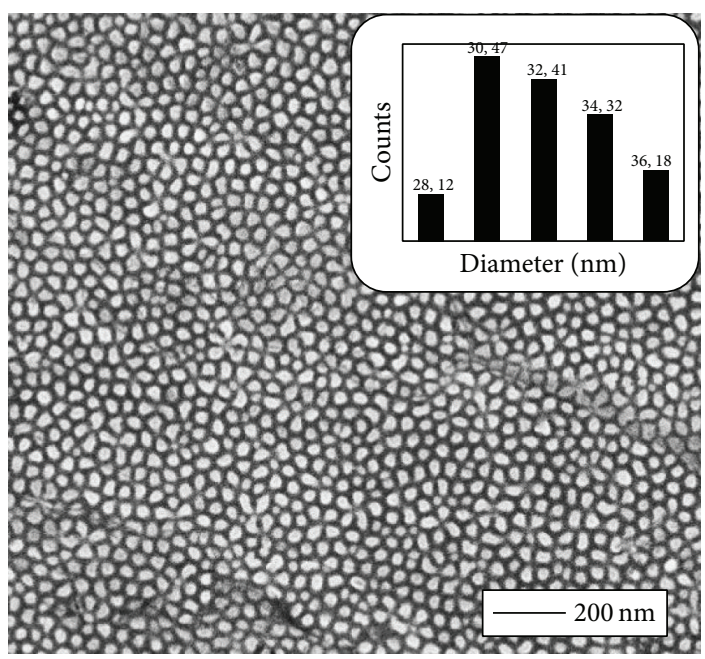

(e)

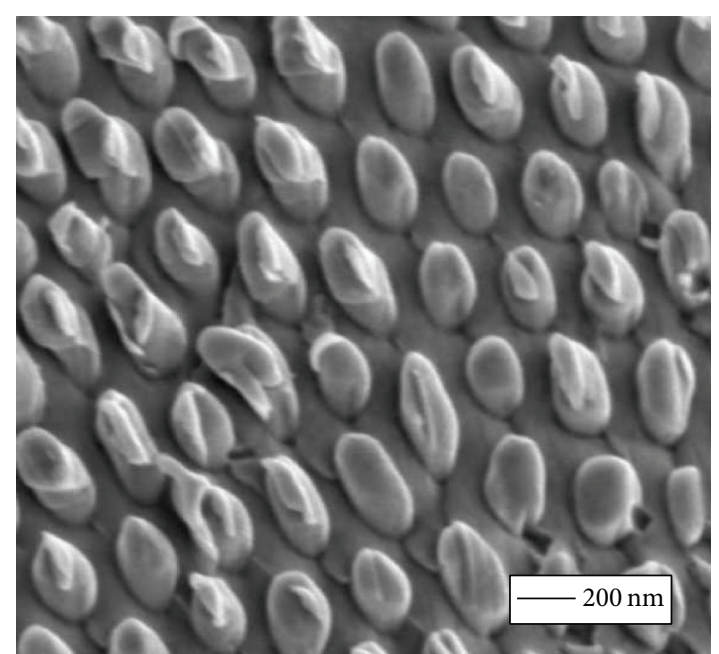

(b)

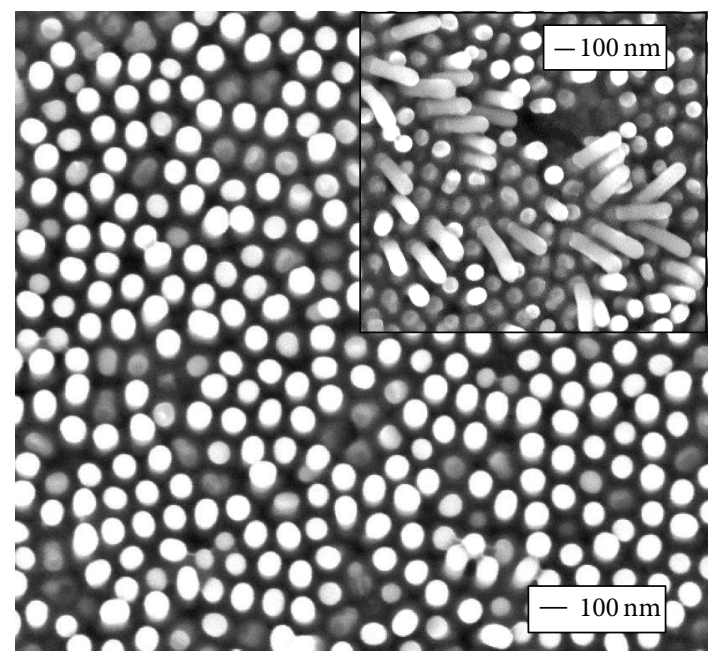

(d)

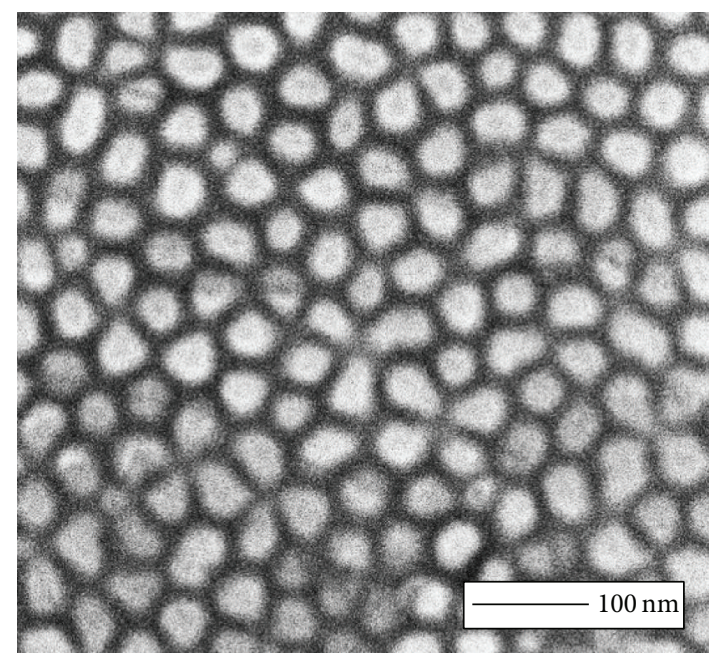

(f)

FIGURE 3: SEM images of the Pt-based amorphous nanorods arrays prepared from AAO template with different diameters. (a) and (b): $202.4 \pm$ $27.8 \mathrm{~nm}$; (c) and (d): $88.6 \pm 6.8 \mathrm{~nm}$; (e) and (f): $34.8 \pm 2.4 \mathrm{~nm}$. The insets in (a), (c), and (e) give the diameter histograms of nanorods. (b), (d), and (f) are the magnified local images or angle-tilt images of these nanorods. 


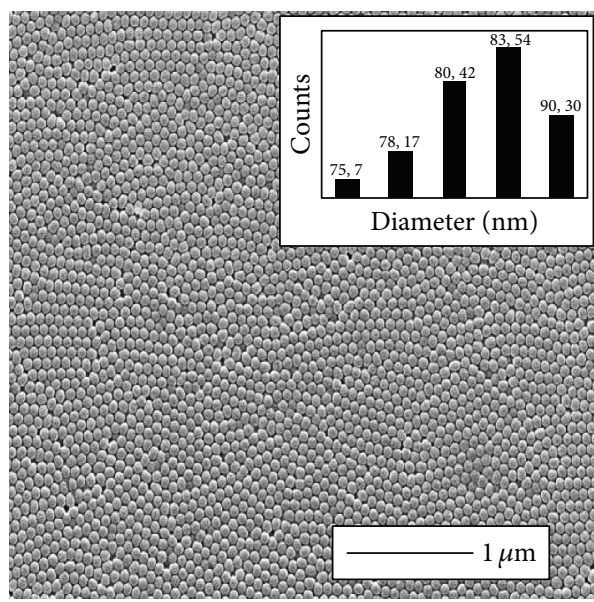

(a)

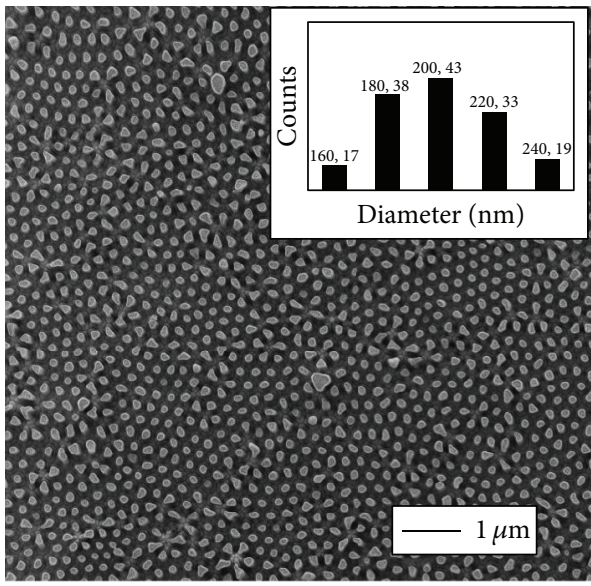

(c)

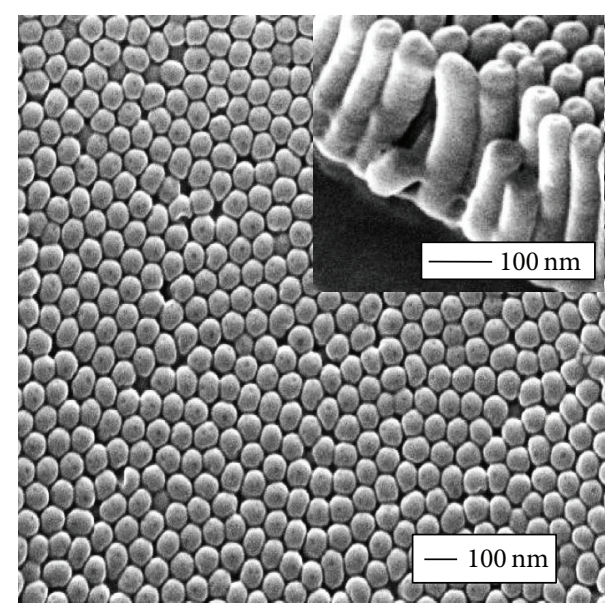

(b)

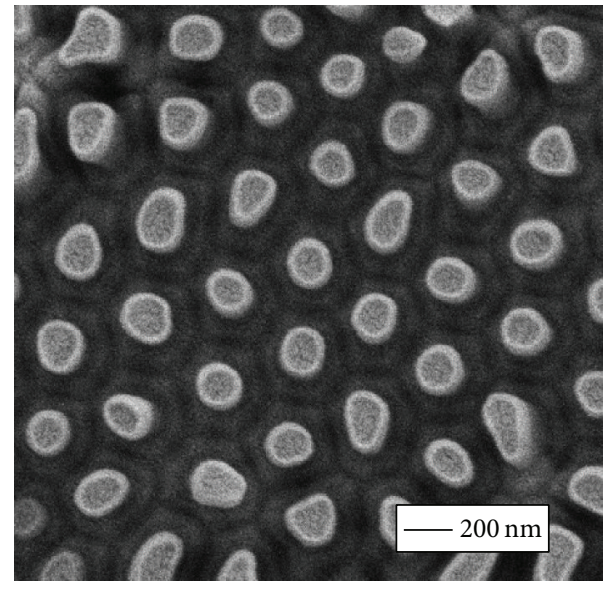

(d)

FIGURE 4: SEM images of the nanorod arrays of SU-8 resin transferred from the AAO template with pore diameter of $82.4 \pm 3.4 \mathrm{~nm}((\mathrm{a})$ and (b)). The inset is the magnified local images of these nanorods. SEM images of the nanorod arrays of PMMA transferred from the AAO template with pore diameter of $198.7 \pm 31.5 \mathrm{~nm}((\mathrm{c})$ and $(\mathrm{d}))$.

images of nanorod arrays made of PMMA plate transferred from AAO template pore diameter of $202.4 \pm 25.4 \mathrm{~nm}$. The diameter of these nanorods is about $198.7 \pm 31.5 \mathrm{~nm}$. The side view of SU-8 nanorod arrays gives an aspect ratio about 6, indicating that the SU-8 resin has a good filling ability.

The nanopore films can be further prepared using these nanorod arrays as master molds. The fabrication procedure using Pt-based nanorod arrays as master molds is demonstrated as below. The HMDS of about $100-200 \mathrm{~nm}$ (used as tackifier) and the positive photoresist ILR-1050 resin of about $300 \sim 400 \mathrm{~nm}$ are spin-coated on the Si wafer successively. Then, the Si wafer with these resins is heated at $100^{\circ} \mathrm{C}$ for 30 mins. After that, a Pt-based amorphous alloy plate with nanorod arrays is placed on the dry ILR-1050 resin and heated to $140^{\circ} \mathrm{C}$ (just above $T_{g}$ of ILR-1050 resin). Then, pressure about $15 \sim 20 \mathrm{MPa}$ is applied on the Pt-based amorphous plate for 20 mins. And then, the Pt-based amorphous alloy master mold and the ILR-1050 resin are gradually cooled to room temperature by conventional air flow and the Pt-based amorphous alloy master mold is released from the ILR-1050 resin mechanically. Finally, the surface of the nanopore arrays made of ILR-1050 resin is cleaned by oxygen plasma and the shallow nanopore arrays are obtained. Figures 5(a) and 5(b) give typical SEM images of the nanopore arrays fabricated by diameter of $88.6 \pm 6.8 \mathrm{~nm}$ Pt-based amorphous alloy nanorod arrays; Figures 5(c) and 5(d) give typical SEM images of the nanopore arrays fabricated by diameter of $198.7 \pm 31.5 \mathrm{~nm}$ PMMA nanorod arrays. The insets in Figures 5(a) and 5(c) show that the diameters of the nanopores are about $94.5 \pm$ $12.2 \mathrm{~nm}$ and $207 \pm 26.4 \mathrm{~nm}$, which are slightly larger than those of nanorods due to the oxygen plasma cleaning and the thermal expansion effect of nanorods at high temperature. These shallow nanopore arrays have great potentials for the ultra-sensitive biosensing after further treatment (chemical functionalization of solid-state nanopores and nanopore arrays and applications thereof) [28] or as masks for deep nanoholes. Nanoparticle arrays can be further fabricated using these nanopore films as templates again. Control 


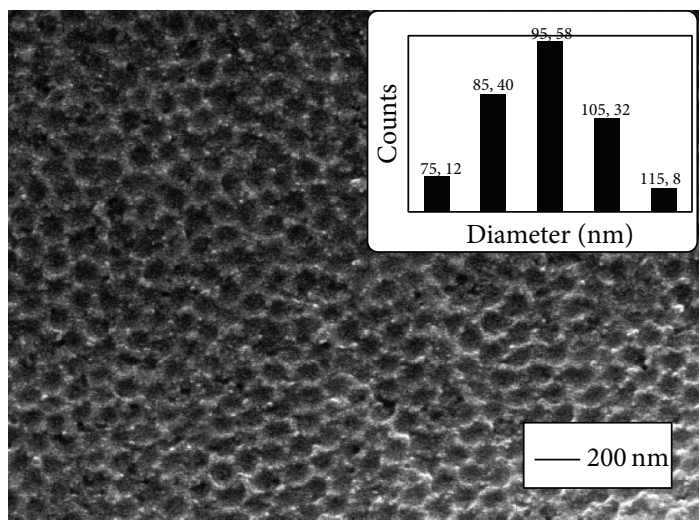

(a)

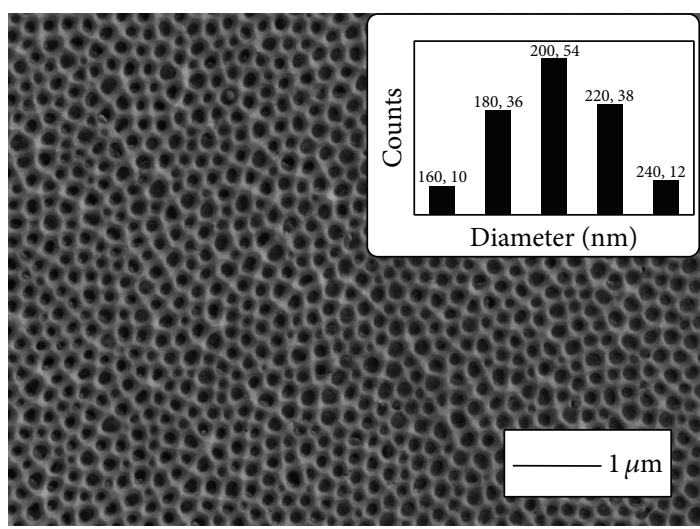

(c)

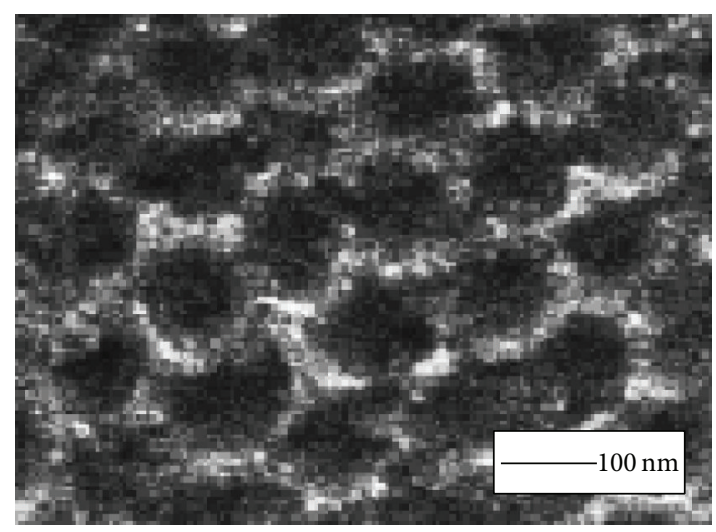

(b)

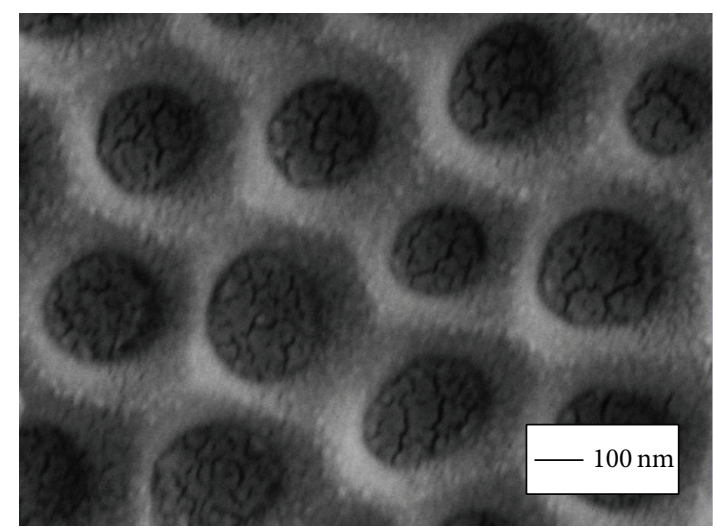

(d)

FIGURE 5: SEM image of the type ILR-1050 photoresist nanopore arrays prepared from Pt-based nanorod arrays. (a) and (b): $94.5 \pm 12.2 \mathrm{~nm}$. SEM image of the SU-8 photoresist nanopore arrays prepared from PMMA-based nanorod arrays. (c) and (d): $207 \pm 26.4 \mathrm{~nm}$. The insets in (a) and (c) give the diameter histograms of nanopores. (b) and (d) are the magnified local images of these nanopores.

of the depth of these nanopores is in progress by tuning the fabrication conditions (e.g., imprinting pressure and temperature, sizes, and interspacing of nanorod arrays).

\section{Conclusions}

The nanorod arrays made of Pt-based amorphous alloys or UV-curing thermosetting epoxy resin are successfully fabricated using AAO template transfer process. Using these nanorod arrays as master molds, the nanopore arrays can be successively transferred into another kind of material, such as ILR-1050 resin on Si wafers (or SU-8 resin on glass slides). This method is suitable for the preparation of shallow nanopore arrays on substrate. This newly developed process enables large-scale fabrication of uniform nanostructures (nanopores or nanorods) based on the template transfer process in which both robust metallic amorphous alloys and thermosetting polymers can be used as constructing materials of master molds.

\section{Conflict of Interests}

The authors declare that there is no conflict of interests regarding the publication of this paper.

\section{Acknowledgments}

This work was supported by NSFC (Grant no. 51371018) and the Fundamental Research Funds for the Central Universities (FRF-BR-15-027A and FRF-BR-14-001B).

\section{References}

[1] C. L. Haynes and R. P. Van Duyne, "Nanosphere lithography: a versatile nanofabrication tool for studies of size-dependent nanoparticle optics," Journal of Physical Chemistry B, vol. 105, no. 24, pp. 5599-5611, 2001.

[2] Y. Song and H. E. Elsayed-Ali, "Aqueous phase Ag nanoparticles with controlled shapes fabricated by a modified nanosphere lithography and their optical properties," Applied Surface Science, vol. 256, no. 20, pp. 5961-5967, 2010.

[3] G. W. Meng, Y. J. Jung, A. Y. Cao, R. Vajtai, and P. M. Ajayan, "Controlled fabrication of hierarchically branched nanopores, nanotubes, and nanowires," Proceedings of the National Academy of Sciences of the United States of America, vol. 102, no. 20, pp. 7074-7078, 2005.

[4] M. A. S. Chong, Y. B. Zheng, H. Gao, and L. K. Tan, "Combinational template-assisted fabrication of hierarchically ordered nanowire arrays on substrates for device applications," Applied Physics Letters, vol. 89, no. 23, Article ID 233104, 2006. 
[5] I. Lombardi, P. L. Cavallotti, C. Carraro, and R. Maboudian, "Template assisted deposition of Ag nanoparticle arrays for surface-enhanced Raman scattering applications," Sensors and Actuators, B: Chemical, vol. 125, no. 2, pp. 353-356, 2007.

[6] Y. Song, W. Yin, Y.-H. Wang et al., "Magneto-plasmons in periodic nanoporous structures," Scientific Reports, vol. 4, article 4991, 2014.

[7] S. Y. Chou, C. Keimel, and J. Gu, "Ultrafast and direct imprint of nanostructures in silicon," Nature, vol. 417, no. 6891, pp. 835$837,2002$.

[8] G. Kumar, H. X. Tang, and J. Schroers, "Nanomoulding with amorphous metals," Nature, vol. 457, no. 7231, pp. 868-872, 2009.

[9] S. Zankovych, T. Hoffmann, J. Seekamp, J.-U. Bruch, and C. M. Sotomayor Torres, "Nanoimprint lithography: challenges and prospects," Nanotechnology, vol. 12, no. 2, pp. 91-95, 2001.

[10] M. T. Rahman, H. Wang, and J.-P. Wang, "Exploration of the direct use of anodized alumina as a mold for nanoimprint lithography to fabricate magnetic nanostructure over large area," Journal of Nanotechnology, vol. 2011, Article ID 961630, 5 pages, 2011

[11] K. O. Aung, C. Shankaran, R. Sbiaa, E. L. Tan, S. K. Wong, and S. N. Piramanayagam, "Achieving high aspect ratio of track length to width in molds for discrete track recording media," Research Letters in Nanotechnology, vol. 2008, Article ID 765398, 4 pages, 2008.

[12] B. Ai, Y. Yu, H. Möhwald, G. Zhang, and B. Yang, "Plasmonic films based on colloidal lithography," Advances in Colloid and Interface Science, vol. 206, pp. 5-16, 2014.

[13] Y. Song, "Fabrication of multi-level 3-dimension microstructures by phase inversion process," Nano-Micro Letters, vol. 2, no. 2, pp. 95-100, 2010.

[14] W. Li, L. Xu, W.-M. Zhao, P. Sun, X.-F. Huang, and K.-J. Chen, "Fabrication of large-scale periodic silicon nanopillar arrays for 2D nanomold using modified nanosphere lithography," Applied Surface Science, vol. 253, no. 22, pp. 9035-9038, 2007.

[15] F. Zhang, J. Chan, and H. Y. Low, "Biomimetic, hierarchical structures on polymer surfaces by sequential imprinting," Applied Surface Science, vol. 254, no. 10, pp. 2975-2979, 2008.

[16] X. Yang, S. Xiao, Y. Hsu, M. Feldbaum, K. Lee, and D. Kuo, "Directed self-assembly of block copolymer for bit patterned media with areal density of 1.5 Teradot/ $\mathrm{Inch}^{2}$ and beyond," Journal of Nanomaterials, vol. 2013, Article ID 615896, 17 pages, 2013.

[17] M. Okada, H. Miyake, S. Iyoshi et al., "Double patterning in nanoimprint lithography," Microelectronic Engineering, vol. 112, pp. 139-142, 2013.

[18] Y. Shen, L. Yao, Z. Li et al., "Double transfer UV-curing nanoimprint lithography," Nanotechnology, vol. 24, no. 46, Article ID 465304, 2013.

[19] Y. J. Song, C. S. S. R. Kumar, and J. Hormes, "Fabrication of an SU-8 based microfluidic reactor on a PEEK substrate sealed by a 'flexible semi-solid transfer' (FST) process," Journal of Micromechanics and Microengineering, vol. 14, no. 7, pp. 932940, 2004.

[20] J. Schroers, "Processing of bulk metallic glass," Advanced Materials, vol. 22, no. 14, pp. 1566-1597, 2010.

[21] S. Mridha, D. L. Jaeger, H. S. Arora, R. Banerjee, and S. Mukherjee, "Atomic distribution in catalytic amorphous metals," Journal of Nanomaterials, vol. 2015, Article ID 632138, 7 pages, 2015.
[22] D. R. Barbero, M. S. M. Saifullah, P. Hoffmann et al., "High resolution nanoimprinting with a robust and reusable polymer mold," Advanced Functional Materials, vol. 17, no. 14, pp. 24192425, 2007.

[23] B. A. Legg, J. Schroers, and R. Busch, "Thermodynamics, kinetics, and crystallization of $\mathrm{Pt}_{57.3} \mathrm{Cu}_{14.6} \mathrm{Ni}_{5.3} \mathrm{P}_{22.8}$ bulk metallic glass," Acta Materialia, vol. 55, no. 3, pp. 1109-1116, 2007.

[24] J. Schroers, "On the formability of bulk metallic glass in its supercooled liquid state," Acta Materialia, vol. 56, no. 3, pp. 471478, 2008.

[25] J. Schroers, B. Lohwongwatana, W. L. Johnson, and A. Peker, "Precious bulk metallic glasses for jewelry applications," Materials Science and Engineering A, vol. 448-451, pp. 235-238, 2007.

[26] M. Aryal, F. Buyukserin, K. Mielczarek et al., "Imprinted largescale high density polymer nanopillars for organic solar cells," Journal of Vacuum Science \& Technology B, vol. 26, no. 6, pp. 2562-2566, 2008.

[27] F. Buyukserin, M. Aryal, J. M. Gao, and W. C. Hu, "Fabrication of polymeric nanorods using bilayer nanoimprint lithography," Small, vol. 5, no. 14, pp. 1632-1636, 2009.

[28] A. Meller and M. Wanunu, "New chemical functionalization of solid-state nanopore, useful for characterizing an analyte, identifying a biomolecule, sensing a chemical environmental, detecting biopolymers, immobilizing enzymes, and localized pH sensing," US Patent: US 9121843-B2, 2015. 

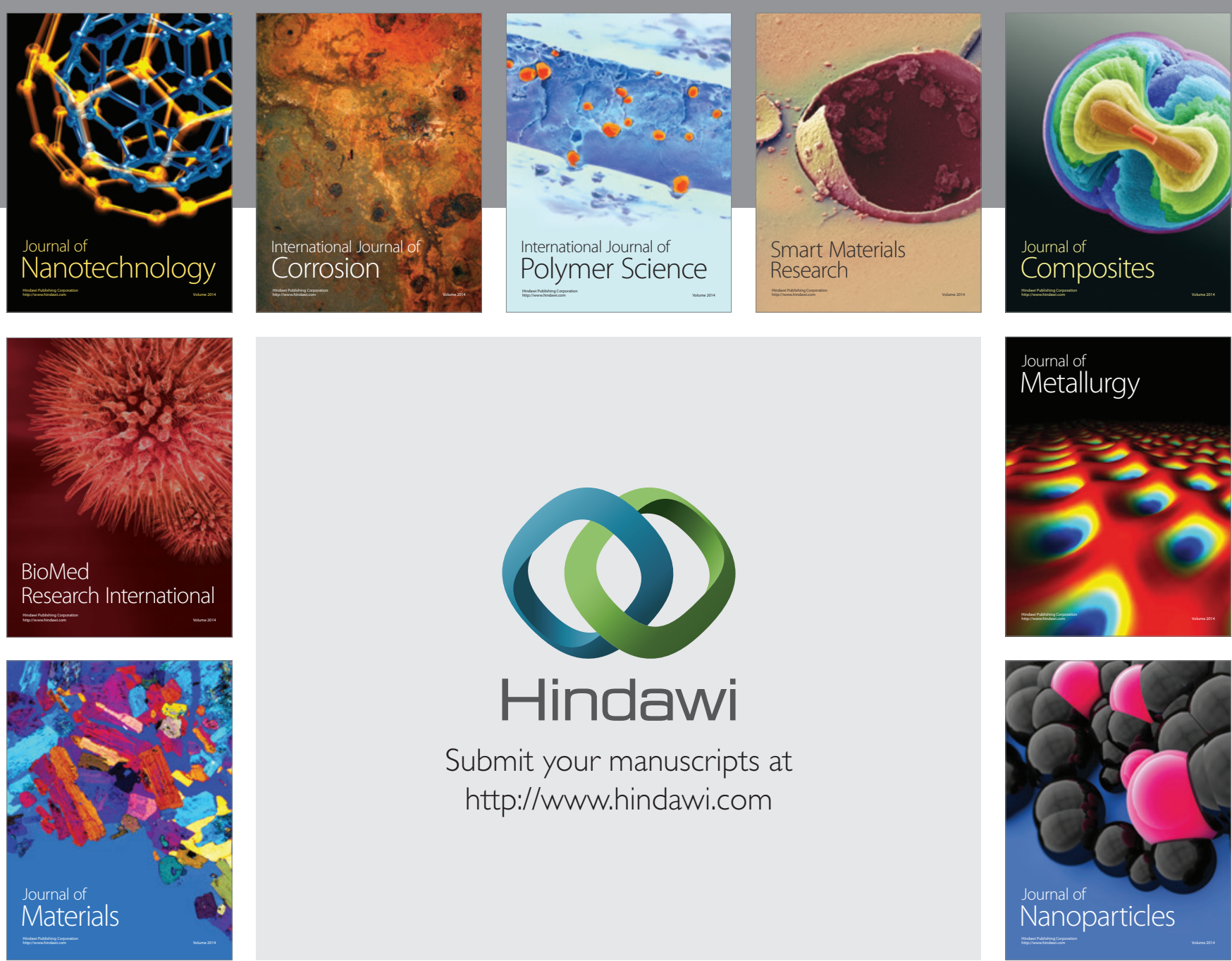

\section{Hindawi}

Submit your manuscripts at

http://www.hindawi.com

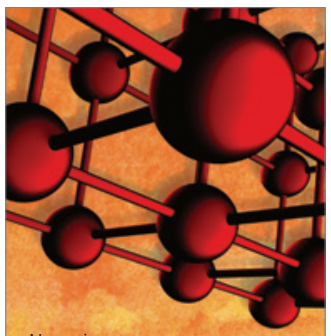

Materials Science and Engineering
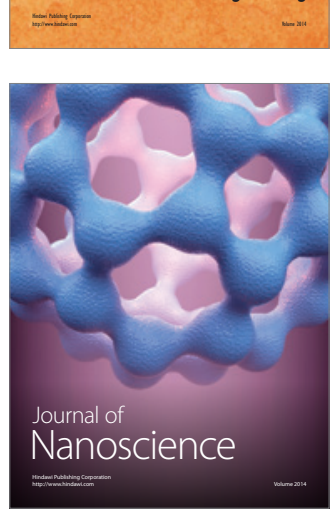
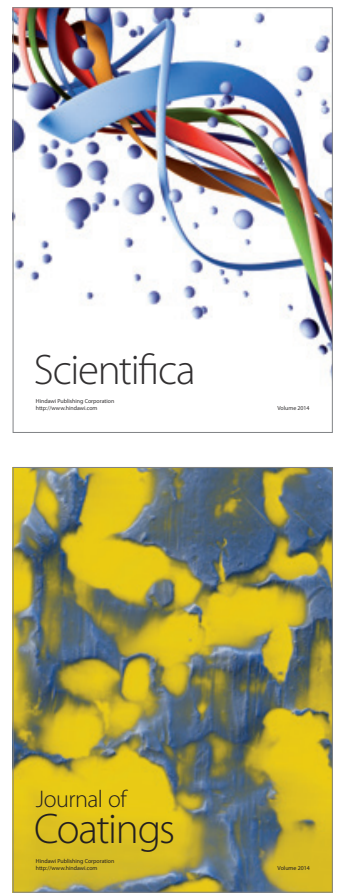
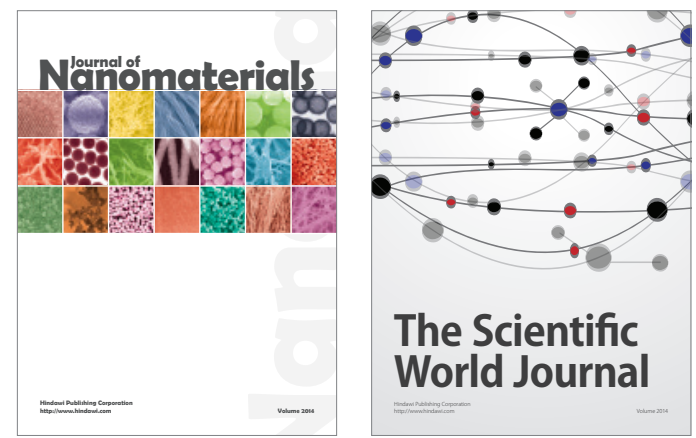

The Scientific World Journal
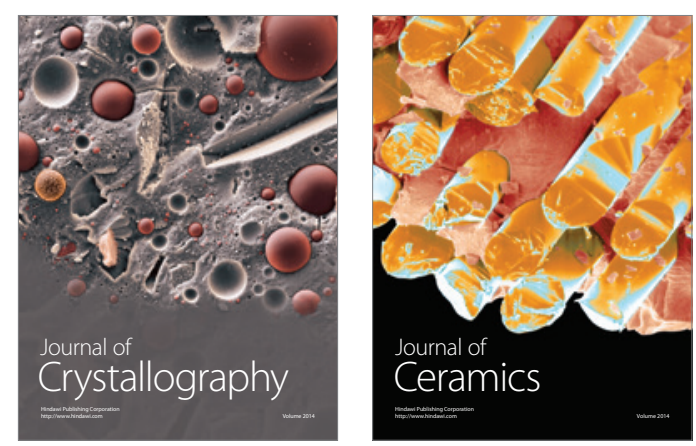
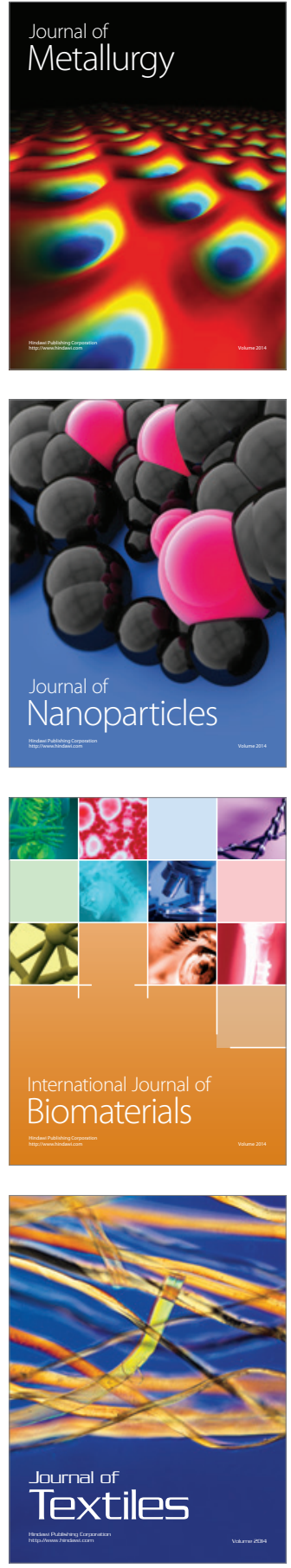